\title{
"NUESTROS HERMANOS MENORES" Y SANTO TOMÁS
}

Ana Mallea

SÍNTESIS - El tema de los vivientes animales es casi ignorado hoy por la filosofia de origen tomista, poco y nada hablan de él exponentes de la escuela en este siglo. Santo Tomás mismo si bien no les dedicó un estudio especial, en reiterados pasajes se refirió al tema como necesario desde la perspectiva de Comentador o de Teólogo. En muchos lugares habla de la vida sensitiva que en estado puro se halla en los animales, como siendo las creaturas vivientes que comparten con el hombre la misma naturaleza genérica que él debe tratar como parte de su consideración teológica o filosófica. Los textos sorprenden por su cantidad, su penetrante observación sobre el reino animal y su carácter filosófico, pudiendo ser la base para un estudio que yo llamaría zoología filosófica. Tal vez uno de los temas más interesantes sea la consideración sobre la potencia sensitiva denominada estimativa, y sus posibilidades para explicar algunos rasgos del comportamiento animal. En la visión creacionista de Santo Tomás nuestros humildes hermanos en el género adquieren todo el valor creatural que les corresponde y exigen del hombre considerarlos como imagen de Dios. Las circunstancias históricas actuales apoyan esta visión revaloradora.

PALABRAS-CLAVE - Tomás de Aquino. Vida sensitiva. Animales. Creacionismo. Creaturas.
ABSTRACT - The subject of living animals is almost ignored nowadays by the Philosophy of Thomistic origin; little or nothing is mentined by followers of the school in our century. St. Thomas himself didn't give them a special treatment but in several passages referred to the subject as a need for the perspective of a commentator or a theologian. On many occasions he refers to sensitive life which in pure state can be found in animals, living creatures that share with man the same generic nature he considers a part of this own theological or philosophical concern. Texts are surprisingly numerous, penetrating in observations on the animal kingdom and its philosophical character; they could be the basis for a discipline I would name Philosophical Theology. One of the most interesting matters would be the analysis of the sensitive power called estimation and its possiblities to explain some traits of animal behaviour. According to the St. Thomas creationist vision our humble brothers in gender acquire all the creatural value belonging to them and urge man to consider them an image of God. Historic circumstances nowadys support this revaluing vision.

KEY WORDS - Thomas Aquinas. Sensitive life. Animals. Creacionism. Creatures.

Buenos Aires (Argentina).

\begin{tabular}{|l|l|l|l|l|l} 
VERITAS & Porto Alegte & v. 44 & n. 3 & Setembro 1999 & p. 633-648
\end{tabular}




\section{¿Por qué conocer los animales?}

No es un tema intelectual como otros; para comprender a nuestros hermanos menores es casi necesario sensibilizarnos hacia ellos y mirarlos como creaturas valiosas en sí mismas.

Leo en Tobías 1-14 sobre la misión que encomienda el padre a su hijo Tobías. Debe ir a una región lejana y cobrar una deuda familiar; y para su seguridad en el camino debe ir acompañado. Es así como se presenta el ángel Rafael bajo la apariencia de un buen muchacho y juntos emprenden la marcha.

Dice la Escritura que el perro los acompañaba y caminaba detrás. No dice un perro sino el perro. Obviamente era el perro de Tobías, no de algún otro miembro de la casa pues se hubiera quedado. Caminaba detrás, o sea no era un cachorro juguetón, era un perro adulto aunque joven.

Si Rafael era la seguridad que reclamó el padre a Tobías ¿para qué un perro? Bastaba y sobraba con un ángel, aunque nadie supiese que lo era. Sin embargo, alguna función cumplía, ¿cuál?

Ese perro, diríamos hoy, era la mascota de Tobías. No podía no ir con él a todas partes, estar a su lado era lo natural y así lo vieron Rafael, el padre, la madre, luego Sara y su familia, todos aceptaron la situación. El perro hizo también el viaje de regreso, siempre caminando detrás.

A pesar de haber un ángel protector el perro era una compañía, acompañaba a Tobías y al ángel, y la presencia del ángel no anuló o suprimió la utilidad y la dedicación del perro.

Este episodio aparentemente tan común de una mascota siguiendo a su amo, adquiere por las circunstancias una significación muy particular.

El ángel Rafael lo dejó acompañarlos aunque estaba él como guardián del viaje; la presencia del perro tenía otro sentido.

¿Cuál es ese sentido que hasta el ángel respeta y más aun, pareciera favorecer?

Pensando filosóficamente ¿cuál es el sentido del animal no sólo en la vida humana sino en la creación misma, en la totalidad de lo creado?

Otro ejemplo tomado de S. Francisco añade a lo propuesto. El Santo tenía a los peces por confidentes y a veces buscaba a sus hermanos menores como consuelo.

Es decir, estudiar a los vivientes sensitivos tiene la doble vertiente de su conocimiento y de desentrañar el significado de su presencia en la creación y al lado del hombre. El teólogo buscará el sentido teológico; el filósofo, el filosófico.

\section{La visión creacionista}

Para S. Tomás el hombre es un microcosmos: contiene en sí todos los grados de perfección del universo. La naturaleza inferior al hombre dice relación al hombre. "Las plantas son para los animales y los animales para el hombre", así lo constatan además varios textos bíblicos y la filosofía cristiana en general.

Santo Tomás, Suma contra gentiles, libro III, cap. 22, 2030. 
La multiplicidad casi infinita de animales que pueblan y han poblado el planeta es para desarrollar las perfecciones que Dios puso en su idea de especie, dice S. Tomás, porque ninguna en particular agota la perfección de la especie. Entonces cada ejemplar animal aporta a ese mosaico de perfecciones, cada individualidad es valiosa y cumple su función en el espejar una perfección de Dios. A la especie humana le ocurre lo mismo, añadiendo un significado de fe: la generación se ordena a la multiplicación de los hijos de Dios. ${ }^{2}$

Pero el hombre no es el centro del universo ni ninguna parte de la creación lo es. Dice Mons. Canciani "cada ser es un centro del universo".

En la visión creacionista teológica la creación entera se dirige a o es atraída hacia un punto al que se llama de múltiples maneras: nuevos cielos, nueva tierra, punto omega, que atraerá hacia sí todas las cosas, tanto las de los cielos como las de la tierra, mientras los dolores de parto de la creación en su estado actual son gemidos que desaparecerán en ese último día del triunfo total de Cristo en todo. ${ }^{4}$ Todas las cosas en el plan divino, ¿acaso no incluye a nuestros hermanos menores?

Si consideramos así el universo creado pero limitándonos al enfoque filosófico, el antropocentrismo se redimensiona casi sólo, como se redimensiona el sentido de los reinos animal y vegetal. La visión creacionista, el influjo de la zoología aristotélica y la noción "estoica del apetito natural hacen que S. Tomás se mueva sobre una línea de antropocentrismo moderado". ${ }^{5}$

S. Tomás tiene una visión creacionista del universo y su mira es teológica. Por eso si bien son muchos los lugares donde menciona a los animales, lo hace no por estudiarlos en sí mismos sino como un escalón hacia el estudio del hombre, que como creatura racional es la voz de la creación en orden al último fin del universo.

Los textos sorprenden por su cantidad, muchos por los datos de buena observación sobre el reino animal y su carácter filosófico, pudiendo ordenarse como punto de partida para un estudio de estos vivientes en sí mismos y constituir una zoologia filosófica con valor propio. En la visión creacionista de Santo Tomás nuestros humildes hermanos en el género adquieren todo el valor creatural que les corresponde y exigen del hombre considerarlos como imagen de Dios. Las circunstancias históricas actuales apoyan esta visión revaloradora.

S. Tomás teólogo, filósofo y comentador aportan al tema.

Santo Tomás, El mundo de los espíritus. Cuestión disputada sobre las creaturas espirituales, art.6, c., Buenos Aires, Ediciones del Rey, 1995, traducida por Ana Mallea, prólogo de Juan Enrique Bolzán, notas y estudio preliminar Celina Lértora Mendoza, p. 81.

3 Mons. Mario Canciani, Nell ' Arca di Noè. Religione e animali, Fos-Epsilón Ed., Buenos Aires, 1992, p. 82.

San Pablo, Efesios, 1, 10.

5 M. Canciani, op. cit., p. 83. 


\section{Textos significativos de S. Tomás en diferentes contextos temáticos}

Las menciones a los animales en el universo tomasiano son citadas ahora asistemáticamente, se las encuentra dispersas en textos, lugares y contextos muy dispares según la obra que los nombra por muy variados motivos.

En el Comentario de la Etica a Nicómaco ${ }^{6}$ más de 40 veces, casi todas comentando una alusión previa de Aristóteles, menciona a los animales en un contexto ético o bien de antropología filosófica, mostrando la naturaleza común entre el hombre y el animal y desde allí despegar hacia lo diferente en esencia entre ellos. Los mismos sentidos que hallamos en ambos, como la imaginación, la memoria, la estimativa (que le proporciona al animal el grado de vida más alto) adquieren en el hombre al estar unida la inteligencia a lo sensible, una perfección que no tienen en el animal. Los sentidos le proporcionan al hombre no sólo funciones biológicas sino también funciones intelectuales, ${ }^{7}$ por eso aparecen profundamente modificados. Esto no quiere decir que ese grado de vida más alto no le dé también al animal posibilidades abiertas, como veremos.

S. Tomás compara comportamientos, relaciona, muestra lo similar entre los niños y los animales, lo diferente en otros casos y pone ejemplos que denotan facilidad para el conocimiento de lo particular, tanto en lo ético como en lo humano y lo animal. Con todo, reitero, nunca habla de los animales porque los estudie en sí mismos sino en relación con el hombre. Destaca la diferencia especifica entre ambos y ésta por supuesto sobresale por sobre la humilde vida sólo sensitiva de los vivientes animales.

\section{Compara comportamientos entre el animal y el hombre}

Cuando habla de los hombres cuyas costumbres decaen hacia la vida pasional y sensitiva que hay en ellos, los compara a los animales diciendo que se asimilan a las bestias. ${ }^{8}$ Pero la bestia como tal por ser así no se desvía de su naturaleza animal, sin embargo su vivir es tomado ahora por la semejanza de los hombres perversos con algunas de ellas. Aunque por este ejemplo cabe entender también que el perverso se denigra al rebajarse del bien ético humano.

En otro pasaje al hombre perverso se lo compara a la bestia en desmedro del hombre justamente por su superioridad óntica. Este es peor porque un solo hombre malo puede hacer diez mil veces más mal que la bestia, al estar dotado de razón para concebir e imaginar diversas maldades. ${ }^{9}$

6 Citaré esta obra de Santo Tomás según la edición leonina, Roma, 1969, pues la nueva versión en español está en prensa y la primera agotada.

7 Jacques Maritain lo interpreta como los sentidos inteligenciados, es decir, penetrados de inteligencia, por ej. al captar algo bello, Arte y Escolática, Buenos Aires, 1983, Club de Lectores, c. 5, nota 56 , p. 164. Esto mismo en general lo enseñaba Mons. Guillermo Blanco en sus clases de Antropologia Filosófica en la Universidad Católica Argentina.

8 Santo Tomás, Com. de la EN., Libro X, lección xiv, n. 1504, p. 599.

Ib. Libro VII, lección vi, n. 985, p. 407. 
"[...] de alguna manera [los animales] participan de las operaciones de las virtudes morales, como el león del acto de fortaleza y el de ser liberal o espléndido, o la cigüeña del acto de amor de los padres". ${ }^{10}$ La amistad conyugal en un aspecto y el amor a la prole competen a la naturaleza común del hombre y el animal." "Hay una amistad natural entre el que genera y. lo generado, no sólo en los hombres sino también en las aves que por largo tiempo se dedican a la crianza de la prole, al igual que sucede en otros animales. También la hay entre los que pertenecen a una misma familia o especie en cuanto participan de las costumbres y de la mutua compañía. ${ }^{12}$ Importantes cualidades que esperan ser estudiadas.

"Los que se exceden en las burlas o bromas del esparcimiento son llamados bromistas groseros o también ladrones de templos, a semejanza de las aves de rapiña que sobrevolaban los templos para llevarse las entrañas de los animales inmolados. ${ }^{\text {"13 }}$ A raíz de la similitud muestra el sobrevolar o volar en tomo a como algo muy propio de los buitres por ejemplo, cuyo sentido los lleva al olor de la carne muerta.

Hay una preciosa referencia a la ira animal aunque en un contexto de comparación con la verdadera fortaleza humana. Es una mirada tan penetrante que añadir, como lo hace, que no se trata de la verdadera fortaleza estaría de más si estuviéramos en un estudio de zoología filosófica.

"Dice (Aristóteles) que las fieras acometen los peligros en razón del dolor, o sea de los males que padecen en acto, por ejemplo cuando se les hace daño; o por el temor de lo que han de padecer; como cuando temen ser heridas o dañadas, incitadas a la ira atacan a los hombres. Puesto que si estuvieran en la selva o en los pantanos no serian dañadas ni temerian serlo y así no atacarian a los hombres. De esto se desprende claramente que no hay en ellas verdadera fortaleza porque son impelidas a los peligros sólo por el dolor y el furor, aunque nada prevean de los peligros, como los que por elección obran valerosamente. Pues si los animales que actúan por pasión fuesen fuertes, por pareja razón también serian fuertes los asnos que por la concupiscencia de su comida cuando están hambrientos no se apartan de la pastura aunque los apaleen. De modo similar los adúlteros por la concupiscencia de lo venéreo acometen con muchas osadías; no obstante, no hay en ellos verdadera fortaleza, porque no obran en razón de la elección de un bien sino por pasión. Así se ve con claridad que tampoco los animales, que en razón del dolor son impelidos a los peligros, tienen verdadera fortaleza."

Concluye este punto afirmando que "entre todas las pasiones, la fortaleza debida al furor parece ser más connatural a la verdadera fortaleza... ${ }^{4}$ Revertiendo el argumento, la ira animal como fuente de fortaleza es en los animales verdadera fortaleza animal.

\footnotetext{
10 Ib., Libro X, lección xii, n. 1491, p. 592.

11 Ib., Libro VIII, lección xii, n. 1233-34, p. 488.

Ib., Lección i, n. 1082, p. 443.

Santo Tomás, Com. de la EN., Libro IV, lección xvi, n. 601, p. 248.

Op. cit., Libro III, lección xvii, n. 380, p. 173-4.
} 
En este pasaje hay además una alusión a la agresión humana con respecto a nuestros hermanos menores y las consecuencias de esta acción, que llevaria a tocar el gran tema actual de la crueldad humana hacia los animales. Algunos hombres para no incitar la peligrosa represalia de la ira animal, sencillamente los matan por los colmillos de marfil, la piel manchada, los cuemos y demás por sus supuestos poderes mágicos, afrodisíacos, etc. Sobre este asunto da S. Tomás una de las causas filosóficas del valor o disvalor de una vida animal con respecto al hombre. Las cosas "no son evaluadas según la dignidad de su naturaleza: de otro modo un ratón que es un animal sensible tendría un precio mayor que una perla que es algo inanimado, sino que el precio de las cosas se impone según la necesidad de su uso que tengan los hombres". ${ }^{15}$ La matanza actual de algunos animales casi hasta el exterminio de su especie se debe a la necesidad que los hombres tienen de los atributos de la naturaleza animal por razones de lucro o algún otro motivo injusto, o sea la indigencia humana sin discreción manda como sin límites en estos casos. Inspirándome en S. Francisco de Asís diría que esa cruel matanza es realmente un fratricidio.

$\mathrm{S}$. Tomás se opuso a la crueldad con los animales ${ }^{16}$ pero en el pasaje que sigue constata un comportamiento que tal vez vio realizado repetidas veces. "El hombre malo [por sus costumbres envilecidas] debe ser castigado por medio del pesar o el dolor lo mismo que la bestia de carga, como el asno que es conducido a latigazos". ${ }^{17}$ El Santo refleja la costumbre de ese trato cruel, innecesario, en castigo de qué, pues si el asno daba trabajo seria más probable que fuera por el maltrato del hambre, la sed, la debilidad y los golpes a que era previamente sometido. ${ }^{18}$

A su vez $\mathrm{S}$. Tomás muestra cuánto puede lograr el hombre bueno de sus "hermanos menores" animales: Un hombre "es llamado manso por no encolerizarse, casi como domeñado, a semejanza de los animales que deponen su iracundia amansados por las manos de los hombres" ${ }^{19}$ Ejemplificar con los animales es aquí iniciativa de $\mathrm{S}$. Tomás.

Sobre si los animales son felices responde que no acceden a la felicidad humana activa que consiste en las operaciones de las virtudes morales, ${ }^{20} \mathrm{ni}$ acceden a la especulativa por carecer de ejercicio intelectual. ${ }^{21}$ Esta respuesta es lógica considerada desde la perspectiva a partir de la cual S. Tomás trata al animal, pero en mi opinión difícilmente desde allí se descubrirá si son felices o no lo son. Se nota bien aquí el desinterés por conocer al animal por sí mismo que lo hubiera llevado a la pregunta: ¿acceden sin embargo a alguna felicidad propia de ellos, no a la humana que les está vedada?

${ }_{16}^{15}$ Op. cit., Libro V, lección ix, n. 696, p. 294.

16 Santo Tomás, Suma contra gentiles, Libro III, cap. 112, 2868.

17 Santo Tomás, Com. de la EN., Libro X, lección xiv, n. 1504, p. 599.

${ }_{18}$ Algunas de esas bestias de carga, según el Ev. apócrifo del Pseudo Mateo, Cap. XIV, 1-2, le dieron calor a Jesús al nacer, dato que la tradición recogió y plasmó en obras de arte y pesebres navideños.

${ }^{20}$ Santo Tomás, Com. de la EN, Libro I, lección 14, n. 109, p. 52.

${ }^{21}$ Ib., Libro X, lección xii, n. 1491, p. 592. 


\section{Diferencias entre los animales mismos}

Hay un texto bastante conocido pero en mi parecer no pasa de ser una comparación como dice el mismo S. Tomás; que no aporta una base filosófica de distinción: "[...] una especie animal difiere de otra en lo denigrante, porque una de ellas lo es más que otra, v.g. porque tenga una vida más torpe e inmunda, como el chancho más que la oveja, o difiere en la sinamoria, completa estupidez, como una especie es más estúpida que otra, el asno más que el caballo, o difiere en que una es voraz en todo, como el lobo". ${ }^{2}$ No veo la comparación como mostrando propiedades objetivas de las especies.

En otro lugar a raíz de los movimientos locales pone un precioso ejemplo: "el vuelo conviene a las aves, el paso a los que marchan, el salto a ciertos insectos y otros semejantes que difieren según las diversas especies de los principios de los movimientos, pues los animales no tienen todos la misma especie de alma". ${ }^{23}$ Menciona además en este ejemplo una manera de reconocer distintas especies de almas en el reino animal, filosóficamente consideradas.

\section{Los sentidos externos}

Los perros no se deleitan en el olor de las liebres por el olor mismo sino por el alimento que esperan, del que huelen su olor. El león no se deleita en el bramido del buey sino en la acción de comer cuya cercanía conoce por el bramido. Por tanto parece gozar en la voz del buey, pero sucede por accidente. Tampoco el león cuando encuentra un ciervo o una cabra se deleita por verlos, sino por la esperanza de obtener comida. Da S. Tomás la causa de estas observaciones diciendo que los animales no se deleitan según los tres sentidos externos de la vista, el oído y el olfato sino por accidente, o sea en orden al gusto y al tacto. ${ }^{24}$

\section{Mayor perfección animal}

"[...] la virtud torna bueno al sujeto del cual es y torna buena su operación [...]. La virtud del caballo hace bueno al equino y por ella éste hace bien su obra que consiste en correr velozmente, llevar suavemente al jinete y esperar con audacia a los contendientes". ${ }^{25} \mathrm{La}$ audacia la pondriamos hoy en otras referencias, empero aun así es necesaria al buen caballo; dicho de otra forma, un caballo asustadizo, por ejemplo, sirve menos o es menos perfecto como equino.

Otro caso: "[...] una es la perfección de los animales, que consiste en la perspicacia del sentido, y otra la de los árboles, que consiste en su fecundidad" ${ }^{26} \mathrm{La}$ perspicacia del sentido, sobre todo del sentido interno de la estimativa, que es el conocimiento más perfecto que S. Tomás encuentra en el animal, necesario para explicar muchos comportamientos irreductibles, como se verá.

Ib., Libro VII, lección vi, n. 984, p. 406.

Ib., Libro X, lección v, n. 1442, p. 599.

Ib., Libro III, lección xxii, n. 404, p. 182.

Ib., Libro II, lección vi, n. 193, p. 94.

Ib., Libro X, lección vii, n. 1457, p. 572.
} 


\section{La interrelación de las naturalezas y los fines}

La diferente alimentación diversifica el modo de vivir en los animales y en los hombres. Los animales viven juntos en manada o dispersos según lo que conviene a la búsqueda de los alimentos útiles, algunos comen frutas o hierbas, otros son camívoros u omnivoros. Según su alimentación algunos animales viven en inactividad y otros en lucha. Los depredadores deben ser luchadores y vivir dispersos, de otra manera no encontrarían alimento. Los que fácilmente hallan su alimento viven juntos. Como aun entre los carnivoros y los herbivoros no todos gustan de las mismas carnes o frutos, el modo de vivir también difiere ${ }^{27}$. La naturaleza provee de nutrimento a las crias en su primera generación, cuando nacen de huevos, como las aves, ciertos gusanos, las hormigas, las abejas y otros. En estos casos junto con la cría el animal parió tanto alimento cuanto baste para que el recién nacido llegue a ser perfecto, "como se ve en el huevo cuya yema sirve de alimento al pollo, el cual se genera de la clara del huevo, y esto mientras el pollo esté dentro de la cáscara. Lo mismo ocurre en los gusanos". Otros animales, como el caballo, que dan a luz a la cría ya perfecta, durante cierto tiempo proveen de sí mismos el nutrimento llamado leche. Y una vez crecidos las plantas son su alimento. A su vez los animales domésticos o silvestres sirven al hombre para alimento, para cubrirse y abrigarse con las pieles, o bien para fabricar instrumentos con los huesos, los dientes y los cuemos. Plantas y animales sirven por naturaleza para sustento de los hombres. ${ }^{2 \mathrm{a}}$ Para nombrar a los animales usa S. Tomás el género masculino, aun en este pasaje donde se alude claramente a la gallina y a la yegua.

\section{Perspectiva biofisiológica}

En algunos textos del Comentario de la Etica menciona a los animales desde una perspectiva biofisiólogica, y en todos los del Comentario de la Física, desde lo físicofisiológico. En los dos por la parte común que tenemos con los animales en lo corpóreo, la vida nutritiva, los movimientos naturales con principio intrínseco y extrínseco, la automoción y el movimiento local. Las menciones son incidentales, refiriéndose a los animales porque antes los mencionó Aristóteles.

Hablando de los movimientos naturales y no naturales en los seres que se mueven por sí mismos, observa que lo natural según su causa y el modo de moverse de las partes animales es natural para una especie y violento para otra. "Por ejemplo, el hombre flexiona los brazos hacia delante y las piernas hacia atrás, pero los perros, los caballos y otros flexionan las patas delanteras hacia atrás y las posteriores hacia delante. Si se produjera en ellos un movimiento en sentido contrario, sería violento y no natural." ${ }^{29}$

27 Santo Tomás, Comentario de la Política de Aristóteles, Libro I, lección vi, n. 66, Buenos Aires, 1981, Boletín del Congreso de la Nación N 106, traducido por Benito Raffo Magnasco, p. 55.

28 Ib., n. 68, p. 56.

29 Santo Tomás, Comentario de la Fisica, Libro VIII, lección vii, n. 791, p. 535 de la ed. Manietti, TurinRoma, 1965, edición en español en preparación, traducida por Celina Lértora Mendoza. 
"Entre las partes irracionales del alma hay una que se asemeja al alma de las plantas, que es común a todos los vivientes en su nivel de vida más bajo. Esta parte es causa de la nutrición y crecimiento de todos y se encuentra en todos los que se nutren, no sólo una vez nacidos sino aun antes de nacer, es decir, ya la tienen los embriones, que claramente se nutren y crecen, De manera similar esta parte se encuentra en los animales. No sólo en los perfectos que tienen todos los sentidos y se mueven con un movimiento progresivo, sino también en los imperfectos que sólo tienen el sentido del tacto y permanecen inmóviles en el mismo lugar, como las conchillas." "Esta parte del alma obra muy eficazmente al dormir, pues volviendo el calor natural al interior del animal, mientras éste duerme la digestión se realiza mejor." "Siempre que vemos en los animales algún movimiento natural, no se mueven por voluntad [...] quizá la causa de su cambio natural sea el continente: el aire y el cuerpo celeste, como es evidente cuando el cuerpo del animal se altera por el calor o el frío. Dice 'quizá' porque también algo se mueve naturalmente en el animal por un principio intrínseco, como es claro en los cambios del alma vegetativa, por ejemplo la digestión de la comida y las mutaciones subsiguientes, que no siguen a la aprehensión y al apetito. ${ }^{322}$ "La causa de los movimientos naturales puede ser un continente extrínseco, como el cielo y el aire, por los cuales son inmutados exteriormente los cuerpos de los animales; o puede ser algo interior al cuerpo animal, como el aire ingresado por la respiración y el alimento por la comida y la bebida; [...] mientras digieren el alimento duermen a causa de los vapores sueltos, pero cuando el alimento ya se ha digerido y asimilado, y los vapores se han disuelto, los animales despiertan, se levantan y se mueven localmente." ${ }^{33}$

"No es increpable que algunos hombres recurran a los placeres corporales si no tienen otros porque les hacen falta como medicina contra las tristezas, cuando les sobrevienen a causa de los movimientos naturales y las operaciones. Pues el animal está siempre velando vigilante en los trabajos o fatigas. Pero estos trabajos son contristantes [...] ver y oír causan tristeza en cuanto son algo fatigoso, en razón de lo cual el animal necesita dormir descansadamente. Empero no percibimos dicha tristeza pues estamos ya acostumbrados a padecerla continuamente. Sin embargo, ver y oír, aunque traigan fatiga y tristeza natural de parte de los órganos corporales, traen también deleite anímico en razón del conocimiento de lo sensible." ${ }^{34}$

En el viviente hay partes reales o potenciales en virtud de lo cual un aspecto es motor y otro es movido. Sobre esto dice S. Tomás que los seres que se automueven, como los animales, son a la vez movidos, sea por movimientos naturales intrínsecos o extrínsecos, sea por el movimiento local subsiguiente, sea porque su alma se mueve por accidente, y por esta condición no siempre se mueven a sí mismos ni siempre lo hacen del mismo modo. ${ }^{35}$ El movimiento local es el primero

\footnotetext{
Santo Tomás, Com. de la EN, Libro I, lección xx, p. 71.

Ib.

Santo Tomás. Com. de la Física, Libro VIII, lección iv, n. 772, p. 519-20.

Ib., lección xiii, p. 569.

Santo Tomás, Com. de la EN, Libro VII, lección xiv, n. 1073, p. 437.

Santo Tomás, Com. de la Física, Libro VIII, lección xiii, n. 847, p. 569-70.
} 
pues adviene una vez alcanzada la perfección sustancial, comenta S. Tomás, por eso se da en los animales más perfectos. ${ }^{36}$ Menciona también el semen generado por la naturaleza al igual que el animal, que siempre obra por un fin determinado por la naturaleza, alcanzar su especie propia y no cualquier otra. ${ }^{37}$

\section{La estimativa}

Una capacidad cognoscitiva del reino animal le merece a $\mathrm{S}$. Tomás mención especial. Ejemplos actuales: al orangután no le gusta mojarse; cuando llueve con hojas y ramitas se hace una especie de paraguas para guarecerse. El antropoide percibió la utilidad de las ramas como medio para no mojarse. Al chimpancé le encantan las nueces, aprendió a romperlas valiéndose de dos piedras, apoya la nuez sobre una de ellas y con la otra a manera de martillo la percute controladamente hasta abrirla y poder comerla. Una madre rinoceronte dio a luz a una cría y al poco tiempo se negó a amamantarla. Los veterinarios del zoo de Honolulu sin entender su comportamiento tomaron el cuidado de la cría a su cargo. A los quince meses notaron que algo no andaba bien en la pequeña rino. Una tomografía computada mostró una enfermedad neurológica congénita. La sacrificaron para que no sufriera. ¿Cómo lo percibió inicialmente la madre rinoceronte? De alguna manera lo estimó y ante el daño emergente la abandonó. En la Universidad de Ohio se hizo una prueba con un chimpancé llamado Shiva. Shiva sabía contar caramelos y reconocía números impresos de un dígito. Se quería saber empero si era capaz de seleccionar entre dos platillos el que tenía menos caramelos para darlo a una chimpancé, enfrente de él. La prueba falló. Entonces se reemplazaron en los platillos los caramelos por los números impresos. Shiva siempre eligió el del número menor para darlo a la otra. Su mente percibió la relación menor que o mayor que y la aplicó correctamente. S Tomás pone el ejemplo de la oveja que ve el lobo y huye estimándolo como enemigo. Essta percepción la realiza la estimativa. ${ }^{38}$ Aristóteles no la conoció. La estimativa es fundamental para explicar algunos comportamientos no sólo instintivos sino adquiridos, es válida para conceptualizar las pruebas más actuales de la capacidad animal; la considero un gran logro de S. Tomás en cuanto al reino animal. Esta potencia es un sentido interno captador de valores en las cosas con significación para la conducta animal, es la percepción súbita de una relación que responde a una situación dada. El animal ve una relación valiosa, el objeto afectado de un valor, ej. útil para, ese nexo no está en el objeto percibido, el mono ve la rama para alcanzar la fruta como una prolongación de su brazo, como instrumento y con valor de medio para alcanzar su objetivo. ${ }^{39} \mathrm{El}$ chimpancé descubre que arrugando y apretando un puñado de hojas le sirven

\footnotetext{
Ib., lección xiv, n. 860, p. 577.

Ib., Libro II, lección xiv, n. 181, p. 128.
}

38 Santo Tomás, Summa Teológica, I Q 78, 3 y 4; Com. de la EN, Libro VI, lección vi, n. 846, p. 352 ; lección vii, n. 864, p. 359; lección ix, nn. 889 a 892 , p. 367 y 368.

39 Max Scheller habla de conducta inteligente en el animal y le atribuye algunas notas simulares a las que S. Tomás pone en la estimativa, cfr.El puesto del hombre en el cosmos, Buenos Aires, 1957, Losada, p. 54-60. Visto como parte del punto lectura de textos en las clases de Mons. G. Blanco, ver la nota 7. 
como esponja para sacar agua del hueco de un árbol. ¿Cómo percibe la relación de utilidad entre hojas, esponja, y agua? ¿Cómo sabe el animal lo que es nocivo para él? Por ej. percibir la oveja al lobo como enemigo de la especie y de ella como miembro de esa especie. Percibe el valor del objeto, lo nocivo en este caso. Esa cualidad o valor con el cual se reviste el lobo para la percepción interna de la oveja, es objeto de estima. La facultad que percibe esas relaciones concretas de valor es la estimativa, por ejemplo; el valor de útil para o nocivo para o de no nocivo y no útil y la gama de intermedios. Si una gacela ve a un guepardo, su enemigo natural, huye. Empero, si el guepardo está herido o débil, la gacela no lo hace, percibió que en este caso no es nocivo para ella. Por este conocimiento el animal compara, relaciona, prueba, selecciona, excluye, separa, junta, como el orangután cuando estima la utilidad de las hojas-paraguas. En el hombre la cogitativa o razón particular es el equivalente humano a la estimativa animal, porque discurre de uno en otro. El animal no discurre racionalmente ante lo particular como el hombre, pero de alguna manera, compara selecciona, sopesa, calibra, duda, relaciona, desiste o espera el momento oportuno y así compone la situación para obrar, por ejemplo cuando un felino salvaje acecha a su presa para cazarla. "Los animales irracionales que tienen una buena estimativa natural son llamados prudentes." 40 "Aquel que puede considerar adecuadamente lo particular que a sí mismo incumbe es llamado prudente, y a éste se atribuye la prudencia. De allí que por cierta similitud con los hombres, algunos animales son considerados prudentes, pues parecen tener cierta capacidad previsiva sobre su propia vida, no ciertamente a partir de la razón, lo cual pertenece a la prudencia." ${ }^{41}$ No sé en que animal pensaría aquí $\mathrm{S}$. Tomás, pero parece que algunas aves y mamíferos superiores encarnan bien esa previsión estimativa.

\section{Imaginación y memoria}

"[...] no decimos que las bestias son continentes o incontinentes porque no están dotadas de pensamiento universal sino de imaginación y memoria de lo singular. ${ }^{\text {"2 }}$ Muy cerca dice lo mismo de esta manera: "porque las bestias no tienen una opinión universal que las mueva, a la cual es contraria la concupiscencia, sino que se mueven sólo a causa de la imaginación y la memoria de lo particular" ${ }^{43}$ Para S. Tomás lo que percibe la estimativa lo conserva la memoria y lo que perciben los sentidos lo conserva la imaginación. Pues la estimativa capta un valor no percibido por el sentido, y en la memoria, el reconocimiento y ubicación en el pasado, la razón de pretérito que afecta a una experiencia pasada tampoco es percibida por los sentidos. ${ }^{4}$ Cuando ejemplifica sobre por qué sirve u obedece un animal al hombre dice que lo hace porque recuerda la vivencia de temor o amor,

\footnotetext{
40 Santo Tomás, Com. de la EN. Libro VI, lección vii, n. 864, p. 359.

41 Ib., Libro VI, lección vi, n. 846, p. 352.

42 Ib., Libro VII, lección v, n. 970 , p. 400.

$43 \mathrm{Ib}$., Libro VII, lección ii, n. 952, p. 393.

44 Santo Tomás, Summa Teológica, 0. 78, 3.
} 
según fuera malo o bueno para él lo vivido al lado del hombre. ${ }^{45}$ Este ejemplo se encuadra dentro de la concepción de la afectividad animal, que no es conocimiento pero está determinada por èl conocimiento. El conocimiento sensible animal está englobado dentro de un marco valorativo biológico. Lo que el animal vive afectivamente está determinado por un conocimiento valorativo, o sea, a partir de la memoria lo bueno o malo vivido. Y comporta una resonancia orgánica, que es la base de la expresividad animal. En el animal queda pues, un residuo en su alma y en su cuerpo de lo vivido por él, ¿no se nota acaso en las expresiones de cautela y defensa, de temor, de desconfianza, de tristeza o al revés de amor, de confianza, de alegría, o bien de resignación sometida a veces, y de docilidad gozosa, en otros casos? Scheller dice que en todo lo afectivo el animal está mucho más cerca del hombre que en lo que se refiere a la inteligencia. ${ }^{46}$

\section{Algo más}

En el punto más alto al que llega el alma animal o sensitiva, en el conocimiento más perfecto a que llega, no la imaginación, no la memoria sino la estimativa, en ella es como si hubiere una apertura, una capacidad o potencia para relacionarse con la racionalidad humana sin tenerla formalmente. A nuestros hermanos menores se les dice irracionales, expresión poco feliz a mi modo de ver pues en ellos se observa "una racionalidad no humana". ${ }^{47}$ Los comportamientos lindantes muestran su alma sensitiva abierta en su punto más elevado a la estimación de percepciones en relación con el hombre. En los hombres que naturalmente son fuertes y justos "se requiere algo distinto, un bien especial - la virtud moral - para que dichas virtudes se den de un modo más perfecto. Pues esos hábitos naturales o inclinaciones se dan también en los niños y en los animales, como el león que naturalmente es fuerte y libre. No obstante estos hábitos naturales parecen ser nocivos si no los asiste la discreción o buen juicio del intelecto. ${ }^{n 8}$ Ante este necesario buen juicio del intelecto cabe preguntarse hasta dónde se extiende su ámbito de influencia con los animales. Hay un texto del Comentario de la Política de Aristóteles, muy sugerente. "Vemos en efecto que los animales amansados a los que el hombre gobierna son más dignos por naturaleza que los silvestres, en cuanto participan de algún modo del régimen o dirección de la razón. Para todos los animales es mejor que sean regidos por el hombre, pues así en muchos casos obtienen la salud corporal que por sí mismos no hubieran podido obtener, como es evidente por los abundantes alimentos y remedios que los hombres les proporcionan." ${ }^{49}$ Este preciosa noción la aplica S. Tomás a la obtención de bienestar corporal del animal, ya es mucho, pero ¿no podemos acaso encontrar alguna otra aplicación más alta a la que tampoco accederían los animales por sí mismos?

\footnotetext{
45 Santo Tomás, Comentario de la Politica de Aristóteles, Libro I, lección ii, n. 39, Buenos Aires, 1981, Boletín del Congreso de la Nación N² 106, traducido por Benito Raffo Magnasco, p. 41.

46 Max Scheller, op. cit, p. 60

47 M. Canciani, op. cit., p 73.

48 Santo Tomás, Com. de la EN, Libro V1, lección xi, n. 905, p. 375.

49 Santo Tomás, Com. de la Política, Libro I, lección ii, n. 35, p. 38. La frase latina dice: in quantum participant aliqualiter regimine rationis.
} 
Ejemplos. La vida de un ciego o de un discapacitado, su seguridad, su incolumidad dependen muchas veces de un animal que se guía por parámetros dictados por la racionalidad humana durante el entrenamiento. Un perro seleccionado aprende a deponer su curiosidad natural y no se distrae por nada: ni ante un ruido, u otro perro o ante un animal que lo pueda sacar de sí como un gato, o un peligro súbito. Se lo capacita para las rutinas y para afrontar situaciones nuevas y súbitas no en beneficio de su supervivencia biológica sino en beneficio de una vida humana singular. Ha incorporado una actitud similar a la racional sin ser él un ser racional. ¿Cómo podria hacerlo si de alguna manera no tuviera una capacidad muy especial para asimilar los mandatos de la razón humana? Es decir, para participar de alguna manera del régimen o dirección de la razón..$^{50}$

En Teología se llama potencia obediencial a la capacidad por la cual una potencia inferior puede recibir una perfección más alta, que pertenece a una naturaleza más elevada, y a la cual naturalmente no podría acceder. Por ejemplo, el alma a la gracia.

Pregunto: la capacidad obediencial ¿se restringe necesariamente al orden sobrenatural? ¿No podria aplicarse acaso esa noción para explicar algún comportamiento adquirido, por ejemplo, el del perro lazarillo, que es reacio a ser explicado cabalmente de otra manera, o el de algún animal heroico salvador de personas del fuego, el agua y otros. Es decir, el asunto es si esta noción puede extenderse al orden pretematural. Alguna vez, enseña el catecismo, los hombres fuimos elevados al orden pretematural, pero el pecado original nos volvió de nuevo a nuestra desnuda condición humana mortal; y quizá a los animales los despojó también de otras cualidades añadidas a su condición natural. Tema algo olvidado. Pero no parece desatinado extender esta noción al orden preternatural en relación con los animales. ¿Acaso S. Tomás no reconoció la tendencia de la materia a acceder a estadios superiores? ${ }^{51}$ ¿No habló de la capacidad de los animales para participar de la dirección de la razón humana?

Podria objetarse que sólo imaginativamente puede hablarse de la disposición sensitiva animal para recibir o percibir de alguna manera una perfección que excede su naturaleza. Es cierto, pero igualmente habría que ver cuál es el principio interno que hay que poner en el animal para explicar un comportamiento que parece irreductible a otros sentidos. Algunos animales en contacto con el hombre adquieren una impronta casi humana, logran algo a lo que por ellos mismos no acceden, que es esa capacidad como preternatural a su naturaleza, que en la vida humana se da como natural. Ese contacto con el hombre, con un hombre bueno, como se dirá, significa la intervención de la acción de un agente superior de tipo intelectual, principio sin el cual la disposición animal no despierta a algo más. Parece necesario poner este principio de inteligibilidad. Hacer a un animal en concreto partícipe de la dirección de la razón humana debe ser querido por el hombre, de otra manera no parece que el animal se eleve hasta esa participación.

Santo Tomás, Suma contra Gentiles, Libro III, cap. 22, 2030. 
Si la esfera común entre el animal y el hombre aparece en el hombre profundamente modificada por las funciones intelectuales propias del hombre ¿no cabe acaso lo contrario, que la esfera común entre ambos también se modifique profundamente en el animal en contacto con el hombre?

Hay aun otros casos en los que podría jugar la noción de potencia obediencial para explicarlos, por lo menos a veces. Por ejemplo ¿cómo explicar la docilidad del halcón a San Francisco y despertarlo todos los días a las 7 a.m.? ¿Podría acaso hallarse alguna respuesta sin recurrir a la intervención de un milagro sobrenatural?

Tal vez. Lo que en el hombre es natural, su racionalidad, es preternatural a la naturaleza animal. Con todo por una percepción muy especial hacia el hombre desde su naturaleza sensitiva el animal estima sus intenciones. ¡Y vaya si San Francisco lo lograba! Su comunicación con los animales era diferente a la de los demás hombres, pero él tal vez la hacía posible por un algo muy especial, un fuerte lazo emotivo espiritualizado hacia toda la creación, un tierno amor hacia ella, amor que valoraba y enaltecía el valor creatural de cada viviente, encarnado en cada gesto, que alcanzaba y elevaba el marco de referencia animal, sabía cómo hablar a su comprensión, a sus vivencias, a su "prudencia" para comparar y estimar intenciones, que el 'hermano menor' captaba, y por eso tal vez obtenía tan dulces respuestas, mansas y dóciles. Tal vez descubrió que en el fondo los animales gozan no tanto obedeciendo como complaciendo y responden mejor si el obedecer se fusiona con el complacer al hombre. Ambos sabian que el del amor era su lenguaje común, se entendían y se respetaban, confiaban el uno en el otro. Tal vez el Santo muestre así uno de los sentidos que tienen los animales en la tierra junto al hombre: expandir nuestro corazón en el amor hacia ellos como un bien para los dos, pues el trato amoroso hacia ellos es quizá lo que más anhelan estos mendigos de amor. ${ }^{52}$ No es casualidad que muchos santos hayan logrado esa comunicación con los animales, que parece como sobreañadirse a su naturaleza. La visión filosófica de $\mathrm{S}$. Tomás unida a su comprensión del mundo real, abierta a sus posibilidades o potencialidades puede eventualmente dar lugar a hablar de una relación hombre animal como la que tenía S. Francisco. ¿Acaso no dijo que el amor y el temor son decisorios en la relación hombre animal para obtener obediencia y servicio? ? $^{53}$

Por otra parte $\mathrm{S}$. Tomás dice que la virtud se toma según lo máximo que algo puede alcanzar, como si la virtud de un forzudo es levantar pesas de hasta $350 \mathrm{ks}$. eso será lo máximo a lo que extiende su virtud. En el caso de la estimativa animal pareciera que se extiende a la percepción de que para él es útil el dejarse conducir por la mente humana, no porque se lo someta o doblegue por la fuerza o por alguna recompensa de alimento, sino por una apertura o docilidad gozosa, por un amansamiento de su ferocidad en manos de un hombre bueno. ${ }^{54}$ Este es el punto. Esa capacidad preternatural pareciera que está trabada o atada y que se despierta por el contacto entre este animal y este hombre bueno, y pareciera que tanto más se despertase cuanto más bueno fuera el hombre. Una obra de arte, dice S. Tomás puede ser artísticamente buena aun si su autor no lo es, pues la bondad del arte

\footnotetext{
M. Canciani, op. cit., p. 81.

Ver nota 46.

Ver nota 12.
} 
depende de su perfección intrínseca, no de la del autor. En nuestro caso no es así. Pues se trata de una acción referida a un ser viviente que responderá obedeciendo con gozo espontáneo sólo si se percata-a su manera que su subsistencia no corre peligro, y aun más, que puede verse beneficiada. ¿Acaso no lo presienten nuestros hermanos menores cuando se entregan dócilmente a un San Francisco? ¿No dice $\mathrm{S}$. Marcos que durante las tentaciones Jesús "descansaba con las bestias salvajes? $(1,13)$. Es decir, convivía pacíficamente con los animales en el desierto.

"Se cuenta que una hiena que tenía a su cachorro ciego abrió con la cabeza la puerta de la choza donde vivía San Macario de Alejandría. El santo curó de su ceguera al cachorro y luego de amamantar la madre a su crío, ambos volvieron al desierto.

San Simeón el Viejo que vivía en soledad entre las bestias salvajes, ordenó a unos leones, luego de haberlos acariciado, que sirvieran como guía a unos viajeros" ${ }^{\text {} 5}$ extraviados.

Un jilguero jugaba con la barba de San Felipe Neri; en las calles por donde iba apartaba o hacía apartar perros, asnos y otros animales que pudieran ser atropellados o correr algún otro peligro. El animal preferido en el amor era su perro Capriccio, al que tomaba en brazos, lo mismo que a su gata. Amor retribuido, Capriccio por estar con S. Felipe hasta prefería comer algún pan o pastel antes que la carne tiema de gallina que otro le preparaba. ${ }^{56}$

"Sólo quien sabe orar puede conocer el lenguaje de la Creación", decía San Serafino. ${ }^{57}$ Cuenta un testigo ocular que el santo hablaba ese lenguaje al lado de otras creaturas que a medianoche rodeaban al ermitaño: osos, lobos, zorros, liebres, lagartijas, reptiles.

En todos los ejemplos de hombres buenos con animales se destaca por sobre cualquier otra detalle, la obediencia o el complacer gozoso de los animales, su mansedumbre. Pareciera que la plenitud del gozo de vivir de ciertos animales se da unido a su amistad con el hombre. En términos de filosofía podría decirse que esa conducta proviene de la capacidad obediencial preternatural a la que se abre como una máxima posibilidad la virtud estimativa del animal.

\section{Resonancias actuales}

Faltan muchos aspectos sobre los que más ampliamente S. Tomás habla: la afectividad animal, sus vivencias y tendencias, el lenguaje animal, su vivir o su sentir, su darse cuenta o conciencia sensible, su sentido y temor de la muerte, su capacidad de deleite, su discernir sensitivo, lo natural y lo adquirido, los hábitos naturales, los distintos instintos, la amistad conyugal, si su alma subsiste después de la muerte y otros. Aun hay más problemas que esperan al estudioso: la cordura y la locura animal, las condiciones antinaturales de vida, el sufrimiento, el juego, el derecho a la vida. No se puede pasar por alto el problema ético de la cohabitación entre los seres que compartimos la tierra, que exige delimitar con verdad y justicia el derecho de cada parte.

\footnotetext{
55

M. Canciani, op. cit., p.73.

Ib., p. 76.

Ib., p. 72.
} 
"¿Es posible tener una idea del Amor misterioso de Dios por sus creaturas? Este es dado en plenitud incluso a las más ínfimas entre ellas. Cada creatura es un milagro de Gracia. Hay una infinita distancia entre un hombre y un insecto, es cierto. Empero ¿cuánta es la distancia entre el insecto y la nada?"

¿Puede decirse que $\mathrm{S}$. Tomás se refiere a los animales con frialdad, carente de tono afectivo ?" $\mathrm{Tal}$ vez no los sentía como sus 'hermanos menores' pero sí como creaturas que despertaban sentimientos amables, actitud que apreciaba como moralmente deseable. ${ }^{60}$ Los animales con el valor creatural de ser imágenes visibles creadas de Dios es la noción sobre la que puede fundarse una zoología filosófica revaloradora.

\section{Bibliografía}

Mons. Mario Canciani, Nell'Arca di Noè. Religione e animali. Título de la traducción en español: Cristianismo y Vegetarianismo, Buenos Aires, Fos-Epsilón Editora, 1992.

Enrique Denzinger, El magisterio de la Iglesia, Barcelona, Ed. Herder, 1955.

Guillermo Fraile, Historia de la Filosofia, T. I y II, Madrid, BAC, 1975.

P. Réginald Garrigou-Lagrange, O. P. La sintesis tomista, Buenos Aires, Ed. Desclée, 1946, traducción Eugenio S. Melo.

Jacques Maritain, Arte y Escolástica, Buenos Aires, 1983, Club de lectores, traducción María Mercedes Bergadá.

La Sainte Bible, Pańs, Les éditions du cerf, 1956, traduite en français sous la direction de l'école biblique de Jérusalem.

Santo Tomás, Comentario al Libro del Alma de Aristóteles, Buenos Aires, Editorial Arché, 1979, traducción Maria C. Donadio, estudio preliminar de Mons. Guillermo P. Blanco.

Santo Tomás, El mundo de los espinitus. Cuestión disputada sobre las creaturas espinituales, Buenos Aires, Ediciones del Rey, 1995, traducido por Ana Mallea, estudio preliminar y notas de Celina A. Lértora Mendoza, prólogo de Juan Enrique Bolzán.

Santo Tomás, Summa Teológica.

Santo Tomás, Suma contra gentiles.

Santo Tomás, Comentario de la Etica a Nicómaco de Aristóteles, T. XLVII, O.C. Santa Sabina, Roma, 1969, editado por orden de León XIII, Nueva versión en español en prensa, traducción Ana Mallea, estudio preliminar y notas Celina A. Lértora Mendoza.

Santo Tomás, Comentario de la Física de Aristóteles, Ed. Marietti, Turin-Roma, 1965. Primera edición en español en preparación, estudio preliminar y traducción Celina A. Lértora Mendoza.

Santo Tomás, Comentario de la Política de Aristóteles, Libros I, II, III, Buenos Aires, Boletín de la Biblioteca del Congreso de la Nación, $\mathrm{N}^{2} 106,1981$, traducido por Benito Raffo Magnasco.

Max Scheller, El puesto del hombre en el cosmos, Buenos Aires, 1956, Losada, traducción José Gaos.

Fernand Van Steenberghen, Filosofia Medieval, Buenos Aires, Club de Lectores, 1967, traducción M. Mercedes Bergadá.

(Registrado como obra inédita, exp. 983495, Buenos Aires, 1 de junio 1999).

\footnotetext{
Ib., p. 110.

Ib., p. 83.

Santo Tomás, Suma contra gentiles, III, cap. 112, 2868.
} 